\title{
Workshop Pembelajaran Bahasa Mandarin Tingkat Dasar di GKKB Pontianak
}

\author{
Lily Thamrin ${ }^{1)}$ Suhardi ${ }^{2)}$, Lusi $^{3)}$, and Tjen Veronica ${ }^{4)}$ \\ 1),2),3),4) Prodi Pendidikan Bahasa Mandarin, Fakultas Keguruan dan Ilmu Pendidikan, \\ Universitas Tanjungpura, Pontianak, Indonesia \\ Corresponding Author: Lily Thamrin, lily.thamrin@fkip.untan.ac.id
}

\begin{abstract}
Abstrak: Saat ini, belajar bahasa merupakan salah satu hal yang sangat penting untuk meningkatkan kemampuan berkomunikasi. Salah satu bahasa yang banyak diminati adalah Bahasa Mandarin. Untuk mendorong perkembangan pembelajaran bahasa Mandarin bagi masyarakat Pontianak, maka dilakukan Pembelajaran Bahasa Mandarin Tingkat Dasar di Gereja Kristen Kalimantan Barat (GKKB) Pontianak melalui sebuah pelatihan. Peserta pembelajaran bahasa mandarin adalah generasi muda organisasi GKKB Pontianak, dengan jumlah 56 peserta yang tersebar dalam berbagai tingkatan kelas dan umur. Materi pelatihan workshop mencakup pengenalan dasar mengenai Hanyu Pinyin (汉语)), huruf Mandarin (汉字), tata bahasa Mandarin (汉语语法), kalimat sederhana (简单的句子), dan Percakapan Bahasa Mandarin (汉语会话). Pembelajaran bahasa Mandarin ini dilakukan melalui workshop dengan pemberian materi dasar-dasar bahasa Mandarin dan melakukan praktek berbahasa lisan yang dilaksanakan setiap hari senin pada bulan September-Oktober 2019. Hasil yang diperoleh dari workshop pembelajaran bahasa Mandarin ini adalah meningkatnya pengetahuan peserta tentang materi dasar bahasa mandarin dan minat pembelajaran bahasa mandarin.
\end{abstract}

Kata Kunci : Pembelajaran, Bahasa Mandarin, Hanyu Pinyin, Komunikasi, GKKB Pontianak

Abstract: Nowadays, learning languages is an essential thing regarding communication ability. One of the popular languages and used dominantly in the world is Mandarin. To encourage the learning development of Mandarin learning for the Pontianak society, a basic level Mandarin learning Workshop has been held at Gereja Kristen Kalimantan Barat (GKKB) Pontianak. The training participants are the Youth organization of the GKKB Pontianak, with 56 participants spread across various grade levels and ages. The workshop training materials are the basic of Mandarin, which is an introduction to Hanyu Pinyin (汉语拼音), Chinese characters (汉字), Chinese grammar (汉语语法), Simple Sentence (简单 的句子), and conversation in Mandarin (汉语会话). This learning was done through a workshop by providing basic material for Mandarin and conducting oral practice (conversation), which was held every Monday from September to October 2019. The results from this Mandarin learning workshop is the increase participants' knowledge of the Mandarin Basic material and interest in learning Mandarin.

Keywords : Learning, Mandarin Language, Hanyu Pinyin, Communication, GKKB Pontianak

\section{Pendahuluan}

Pembelajaran berasal dari kata "ajar" yang berarti petunjuk yang diberikan kepada orang supaya diketahui (diturut) dan kata "belajar" yang berarti berusaha memperoleh kepandaian atau ilmu, berlatih, berubah tingkah laku atau tanggapan yang disebabkan oleh pengalaman

Submitted: 13.9.2020, Revised: 27.10.2020, Accepted: 28.10 .2020 
(Badan Pengembangan dan Pembinaan Bahasa, 2020). Sedangkan kata pembelajaran itu sendiri adalah proses, cara, perbuatan menjadikan orang atau makhluk hidup belajar. Menurut UU No. 20 Tahun 2003 Tentang Sisdiknas Pasal 1 Ayat 20: Pembelajaran merupakan proses interaksi peserta didik dengan pendidik dan sumber belajar pada suatu lingkungan belajar. Adapun beberapa ahli yang memberikan pengertian tentang "pembelajaran" antara lain:

1. Warsita: suatu usaha untuk membuat peserta didik belajar atau suatu kegiatan untuk membelajarkan peserta didik.

2. Corey: suatu proses dimana lingkungan seseorang secara disengaja dikelola untuk memungkinkan ia turut serta dalam tingkat laku tertentu dalam kondisi-kondisi khusus atau menghasilkan respons terhadap situasi tertentu, pembelajaran merupakan subset khusus dari pendidikan

3. Sudjana: setiap upaya yang sistematik dan sengaja untuk menciptakan agar terjadi kegiatan interaksi edukatif antara dua pihak yaitu antara peserta didik "warga belajar" dan pendidik "sumber belajar" yang melakukan kegiatan membelajarkan.

4. Mulyasa: proses interaksi antara peserta didik dengan lingkungannya, sehingga terjadi perubahan perilaku ke arah yang lebih baik. Dalam interaksi tersebut banyak sekali faktor yang mempengaruhinya, baik faktor internal yang datang dari dalam diri individu, maupun eksternal yang datang dari lingkungan (Syahputra, 2014).

Dalam kehidupan sehari-hari bahasa memiliki peranan yang sangat yang penting dalam kehidupan manusia, dimana bahasa digunakan sebagai alat komunikasi antar manusia yang dapat menyampaikan informasi kepada pihak lain. Selain itu bahasa juga sebagai lambang budaya atau jati seseorang. Bahasa menempati urutan pertama dalam unsur kebudayaan universal. Tidak dapat dipungkiri bahasa merupakan sarana komunikasi yang paling utama di dunia. Di era globalisasi sekarang ini, bahasa menjadi salah satu komponen yang sangat penting dalam membantu pertukaran budaya antar berbagai negara.

Dalam pembelajaran bahasa Mandarin ada empat komponen pembelajaran yang harus dikuasai, yaitu menyimak (听), berbicara (说), menulis (写), dan membaca (读). Sutami (2012) mengatakan bahwa pembinaan dan pengembangan bahasa mandarin perlu dilakukan agar fungsinya sebagai bahasa asing dapat dilaksanakan, dimana dalam pembinaan tercakup kegiatan meningkatkan mutu pengajaran Bahasa Mandarin: 1) Pengembangan kurikulum;2) pengembangan bahasa ajar yang sesuai kebutuhan siswa dan perkembangan metodologi pengajaran bahasa; 3) pengembangan tenaga pengajar yang profesional; 4) pengembangan sarana pengajaran bahasa mandarin yang memadai; 5) pemanfaatan teknologi informasi dalam Bahasa Mandarin. Sehingga dalam pengembangannya sebagai bahasa asing, perlu dilakukan penelitian yang memberi manfaat seperti: 1) Mengembangkan metode pengajaran Bahasa Mandarin di Indonesia guna meningkatkan mutu pengajarannya; 2) Menyusun buku ajar yang sesuai dengan kebutuhan siswa Indonesia; 3) Melakukan penelitian terhadap masalah penguasaan bahasa dibidang leksikok, gramatika, fonologi. Fonetik, semanrik, pragmatik; 4) Meningkatkan kemampuan dan keterampilan mengajar para guru melalui pelatihan; 5) Mengembangkan teori pengajaran Bahasa Mandarin.

Sehingga pembelajaran bahasa mandarin lazimnya pendidik dan peserta didik melakukan kegiatan sebagai berikut : 1) pendidik melafalkan 生词, peserta didik menirukan; 2) pendidik memberi kesempatan kepada peseta didik untuk melafalkan 生词 secara individual atau klasikal; 3) pendidik memberi contoh membaca 课文, peserta didik menirukan; 4) pendidikan memberi kesempatan membaca 课文 kepada peserta didik secara individual dan atau klasikal; 5) pendidik menugasi peserta didik untuk menjawab pertanyan dan membahas jawaban pertanyaan secara 
klasikal; 6) pendidik menjelaskan 语法 kepada peserta didik; 7) peserta didik mengerjakan latihan(Maria, 2017).

Pembelajaran bahasa mandarin mencakup aspek-aspek Percakapan. Percakapan bertujuan agar mahasiswa mampu berkomunikasi guna memperlancar komunikasi dan kerjasama antara dua pihak, yaitu pihak China dan Indonesia. Mendengar bertujuan mahasiswa mampu memahami lawan bicara dalam bahasa Mandarin dengan baik agar tercipta komunikasi dua arah dengan lancar dan menghindari kesalah pahaman. Menulis bahasa Mandarin yang memiliki puluhan ribu karakter sangat penting untuk dipelajari, mengingat banyaknya komunikasi secara tertulis atau korespondensi yang akan terjadi di dunia industri. Pemahaman membaca dalam bahasa Mandarin tidak dapat dilupakan, mengingat banyaknya dokumen maupun catatan perjanjian tertulis yang akan dijumpai dalam dunia industri. Sedangkan Tata Bahasa merupakan aspek yang menunjang dalam keempat aspek di atas. Dengan mempelajari tata bahasa secara terpisah, maka mahasiswa mampu memiliki kemampuan bahasa yang lebih baik. Bahasa merupakan bagian dari budaya, sehingga pengetahuan budaya sangatlah penting untuk dapat lebih memahami satu sama lain dalam menjalin hubungan dengan bangsa lain (Jesslyn and Lystia, 2019).

Haryanti (2011) mengatakan bahwa pembelajaran Bahasa Mandarin di Sekolah bertujuan untuk mengembangkan peserta didik dalam berkomunikasi lisan dan tulis serta untuk memahami dan menyampaikan informasi, pikiran dan perasaan. Melalui pembelajaran Bahasa Mandarin diharapkan peserta didik dapat tumbuh dan berkembang menjadi warga negara yang cerdas dan terampil serta dapat memahami budaya asing guna dikembangkan dalam pembangunan nasional. Dalam kelas Bahasa Mandarin peserta didik juga dimotivasi untuk secara aktif terlibat dalam proses pembelajaran tertutama dalam hal bacaan baik yang berupa media cetak maupun yang berupa media elektronik. Dengan demikian siswa akan mampu memahami budaya orang lain dan akan lebih memahami budaya bangsa sendiri, sehingga mereka akan memiliki konsep berpikir yang lebih kritis. Sehingga dalam pembelajaran bahasa mandarin terdapat dasar dasar yang perlu dipelajari secara rinci dan bertahap. Pembelajaran yang terpaku pada buku, kamus, dan guru membuat siswa kurang efektif dan efisien dalam belajar bahasa Mandarin. Maka diperlukan aplikasi yang mampu untuk membantu dalam pembelajaran bahasa mandarin, agar siswa mudah dan mampu memahami bahasa mandarin.

Pembelajaran bahasa mandarin dapat dilakukan dengan model materi tertentu, seperti model materi ajar membaca bahasa mandarin berbasis bahan otentik. Didapatkan bahwa materi ajar yang digunakan belum memenuhi kebutuhan mahasiswa dan topik-topik dalam silabus sudah baik menurut mahasiswa, tetapi kurang menarik menurut dosen, pemberian bahan otentik sangat diperlukan dalam pembelajaran. Bahan otentik yang digunakan dalam pembelajaran bahasa berupa teks, film, foto, dan sebagainya. Teks pada bahan otentik digunakan karena dianggap menarik, menyenangkan, mencerahkan secara kultural, relevan, dan memotivasi. Dengan teks otentik, pebelajar mengetahui bagaimana bahasa yang dipelajari digunakan dalam dunia nyata. Teks otentik adalah naskah yang pernah ditulis, dibuat, disampaikan oleh seseorang atau suatu lembaga untuk keperluan yang sebenarnya. Bahan yang termasuk ke dalam teks otentik adalah pengumuman, artikel, petunjuk manual, brosur, kemasan, dan lain sebagainya. Pembelajaran bahasa dengan memanfaatkan teks otentik juga dapat mengikis kebosanan dalam belajar (Adji, 2017).

Seorang guru diharapkan mampu memotivasi dan melibatkan peserta didik untuk secara aktif dalam kegiatan pembelajaran terutama dalam mendalami sejumlah bahan bacaan, baik berupa media cetak maupun media elektronik. Peran guru dalam meyampaikan materi ajar maupun sarana media belajar merupakan faktor penting terhadap keberhasilan dalam pembelajaran bahasa mandarin. Media pembelajaran bahasa Mandarin di sekolah pada 
umumnya berupa buku pelajaran (textbook) dan buku latihan soal untuk siswa. Kompetensi dasar berbahasa Mandarin, mencakup empat aspek keterampilan bahasa yang saling terkait, yaitu mendengarkan, berbicara, membaca, dan menulis. Maka di rancang media pembelajaran bangun media pembelajaran bahasa mandarin berbasis mobile learning, agar siswa dapat belajar dimana pun dan kapan pun dengan hanya mengakses melalui web, maka siswa dapat dengan leluasa melakukan pembelajaran bahasa mandarin (Kamil Malik, 2018).

Keberadaan media pembelajaran interaktif dapat membuat suasana proses belajar mengajar yang berbeda dalam kelas, karena materi yang dulu diajarkan dengan ceramah yang bersifat monoton dapat divariasikan dengan menampilkan tayangan berupa integrasi teks, suara, gambar bergerak dan video. Dengan media pembelajaran berbasis multimedia belajar mandiri. Media pembelajaran yang ada sekarang dapat menjadi sumber belajar yang lebih menarik bila dipadukan dengan Teknologi Informasi dan Komunikasi (Loris, 2017). Peneliti lain merancang multimedia pada pelajaran Bahasa Mandarin dengan menggunakan multimedia pembelajaran interaktif, agar siswa dengan cepat memiliki kecakapan dalam menulis, dan dengan mudah mempelajarinya di mana pun dan kapan pun, tanpa harus menunggu pembelajaran bahasa mandarin secara interaksi bersama dengan guru (Susanna, 2013).

Herliana dan Suryadi (2019) mengatakan bahwa proses pembelajaran bahasa Mandarin tidak pernah luput dari bahasa karena dalam interaksinya selalu mengandung berbagai macam tindak tutur yang dilakukan oleh pengajar ataupun oleh peserta didik. Pengajar menggunakan bahasa Mandarin sebagai bahasa utama untuk memberikan contoh kepada mahasiswanya agar selalu belajar berkomunikasi menggunakan bahasa Mandarin. Untuk mengkaji penggunaan bahasa yang digunakan oleh pengajar bahasa Mandarin maka di berlakukan cara tindak tutur, seperti tidak tutur ilokusi. Tindak tutur ilokusi antara lain adalah berjanji, membuat pernyataan, dan menyatakan perintah atau permintaan. Dengan ini dapat meningkatkan pembelajaran bahasa mandarin dari segi aspek berbicara.

Dalam pembelajaran bahasa Mandarin aspek berbicara menduduki posisi yang sangat penting sebagai salah satu komponen kemampuan penguasaan bahasa yang harus dikuasai. Sehingga pelatihan workshop pembelajaran bahasa Mandarian dasar di Gereja Kristen Kalimantan Barat (GKKB) Pontianak dapat membantu para peserta menguasai percakapan dan pemahaman dasar tentang pengetahuan bahasa Mandarin.

GKKB adalah suatu organisasi Gereja Kristen Protestan yang berdomisili di propinsi Kalimantan Barat. GKKB didirikan oleh para misionaris-misionaris dari berbagai negara yang datang melakukan misi pengabaran injil ke Kalimantan Barat. GKKB, dimulai dari tiga gereja yang berdiri secara terpisah di tiga kota utama yaitu Singkawang, Pontianak, dan Pemangkat yang kemudian berkembang luas mencakup wilayah pontianak kota, kabupaten kubu raya, mempawah, singkawang, bengkayang, sambas, sekadau, sintang, melawi dan ketapang.

GKKB Pontianak merupakan salah satu bagian dari organisasi GKKB. GKKB Pontianak dimulai pada tahun 1935 oleh sekelompok orang Kristen asal Tiongkok. Hingga hari ini peserta dari GKKB Pontianak sudah berkembang pesat, dengan jumlah peserta mencapai 2000an yang terdiri dari anak-anak, remaja, pemuda, dewasa madya, dan orang tua. Mayoritas pesertanya adalah keturunan Tionghoa, sehingga kegiatan sering kali dilakukan dalam billingual (dua bahasa), yaitu menggunakan bahasa indonesia dan bahasa mandarin ataupun bahasa dialek tionghoa. Penggunaan bahasa Indonesia diperuntukkan bagi kaum pemuda, remaja dan anakanak, sedangkan bahasa mandarin diperuntukkan bagi orang tua yang tidak begitu menguasai bahasa Indonesia.Kondisi ini disebabkan dalam kurun waktu 30 tahunan tidak diperbolehkan menggunakan tulisan dan Bahasa Mandarin, sehingga kaum pemuda, remaja dan anak-anak sama sekali tidak mengerti Bahasa Mandarin 
Sejak masa pemerintahan Presiden Abdurachman Wahid tahun 2001 larangan penggunaan tulisan mandarin (huruf Tionghoa) telah dicabut, pembelajaran Bahasa Mandarin mulai berkembang dan diminati kembali oleh orang Indonesia. Namun bahasa mandarin hanya dikenal oleh peserta yang berusia lanjut/tua, sedangkan generasi yang muda sama sekali tidak menguasainya. Melihat kondisi perkembangan Bahasa Mandarin di mata dunia, semakin banyak peminat Bahasa Mandarin yang berusaha untuk menguasai bahasa internasional kedua ini. Anak-anak muda GKKB Pontianak juga menyadari pentingnya menguasai Bahasa Mandarin, namun mereka tidak mempunyai wadah untuk belajar Bahasa Mandarin. Namun mereka tidak menemukan wadah yang tempat untuk belajar Bahasa Mandarin. Peneliti melihat adanya kebutuhan masyarakat akan pembelajaran bahasa mandarin, maka peneliti berinisiatif menyelenggarakan workshop pembelajaran bahasa mandarin tingkat dasar bagi anak muda GKKB Pontianak.

Saat sebelum dilakukan workshop, peserta masih belum menguasai bahasa mandarin tingkat dasar dan memiliki pengetahuan yang kurang tentang keuntungan setelah menguasai Bahasa Mandarin. Untuk itu, kegiatan pengabdian sebagai salah satu dharma dalam Tri Dharma Perguruan tinggi dilakukan untuk menyadarkan peserta terkait pentingnya menguasai bahasa Mandarin tingkat dasar, serta meningkatkan motivasi peserta untuk mempelajari Bahasa Mandarin lebih baik lagi. Adapun luaran dari kegiatan pengabdian ini adala meningkatnya motivasi generasi muda GKKB Pontianak untuk mempelajari Bahasa Mandarin dan meningkatnya pemahaman terhadap pentingnya menguasai Bahasa Mandarin.

\section{Metodologi}

\section{A. Kerangka Pemecahan Masalah}

Alternatif pemecahan masalah yang dilakukan adalah memberikan workshop pembelajaran bahasa mandarin tingkat dasar dengan memberikan materi "Short Term Spoken Chinese", sehingga peserta menguasai pengetahuan dasar berbahasa mandarin secara sederhana.

\section{B. Realitas Pemecahan Masalah}

Persiapan sebelum pelaksanaan Kegiatan pengabdian pada masyarakat ini adalah sebagai berikut:

1. Melakukan studi pustaka yang relevan.

2. Menentukan waktu pelaksanaan dan lamanya kegiatan pengabdian.

3. Menentukan dan mempersiapkan materi yang akan disampaikan dalam kegiatan pengabdian masyarakat.

Kegiatan yang dilakukan dalam kegiatan Pengabdian Kepada Masyarakat disajikan pada Tabel 1.

Tabel 1. Materi dan Jadwal Pelaksanaan Kegiatan

\begin{tabular}{|c|c|c|c|}
\hline No & Kegiatan & Tanggal & Durasi Waktu \\
\hline 1 & Pembukaan Workshop & 16 September 2019 & $1 \mathrm{jam}$ \\
\hline 2 & Pertemuan 1 Напуи Pinyin & 23 September 2019 & $2 \mathrm{jam}$ \\
\hline 3 & Pertemuan 2 Huruf Mandarin & 30 September 2019 & $2 \mathrm{jam}$ \\
\hline 4 & $\begin{array}{l}\text { Pertemuan } 3 \text { Tata bahasa: Kalimat } \\
\text { Sederhana }\end{array}$ & 7 Oktober 2019 & 2 jam \\
\hline 5 & $\begin{array}{l}\text { Pertemuan } 4 \text { Percakapan Bahasa } \\
\text { Mandarin }\end{array}$ & 14 Oktober 2019 & $2 \mathrm{jam}$ \\
\hline 6 & Penutupan Workshop & 15 Oktober 2019 & $1 \mathrm{jam}$ \\
\hline
\end{tabular}


Tabel 2. Alokasi Waktu Kegiatan Pengabdian Kepada Masyarakat

\begin{tabular}{llcc}
\hline Kegiatan & \multicolumn{3}{c}{ Tahun 2019 } \\
\cline { 2 - 4 } & 9 & 10 & 11 \\
\hline 1. Perumusan Awal Kegiatan PKM & $\mathrm{X}$ & & \\
2. Penyusunan Proposal PKM & $\mathrm{X}$ & & \\
3. Survey Lapangan & $\mathrm{X}$ & & \\
4. Perancangan Kegiatan PKM & $\mathrm{X}$ & & \\
5. Pelaksanaan Kegiatan PKM & & $\mathrm{X}$ & $\mathrm{X}$ \\
6. Pelaporan & & $\mathrm{X}$ & $\mathrm{X}$ \\
\hline
\end{tabular}

\section{Khalayak Sasaran}

Pengabdian Kepada Masyarakat dilakukan oleh tim dosen yang melibatkan mahasiswa prodi Pendidikan Bahasa Mandarin dengan melakukan kegiatan yang berfokus pada pembelajaran bahasa mandarin bagi generasi muda organisasi GKKB Pontianak yang sudah dikoordinasikan terlebih dahulu dengan pihak pimpinan organisasi. Kegiatan dilakukan pada waktu yang telah disepakati bersama, bertempat di Aula Betlehem lantai tiga gedung GKKB Pontianak. Perserta yang mengikuti workshop sebanyak 56 orang, yang berusia 16 tahun ke atas.

\section{Metode Yang Digunakan}

Kegiatan Pengabdian kepada masyarakat dilakukan dengan sosialisasi pembelajaran bahasa Mandarin dengan pemberian materi dasar-dasar bahasa mandarin dan melakukan praktek berbahasa lisan (conversation). Hal ini dilakukan agar warga khayalak sasaran menyadari bahwa berbahasa mandarin tidaklah sesulit yang dibayangkan dan termotivasi untuk mempelajari bahasa Mandarin lebih intensif. Bebeberapa materi dasa nada, percakapan, dan pengenalan huruf pada bahasa Mandarin disajikan beruturut-turut pada Gambar 1 sampai dengan Gambar 3.

\section{汉语的声调（四声） Nada (Empat nada dalam Bahasa Mandarin)}

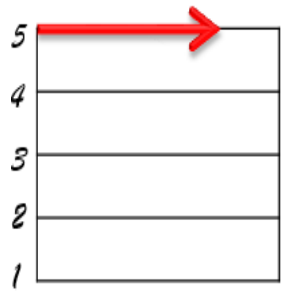

$m \bar{a}$
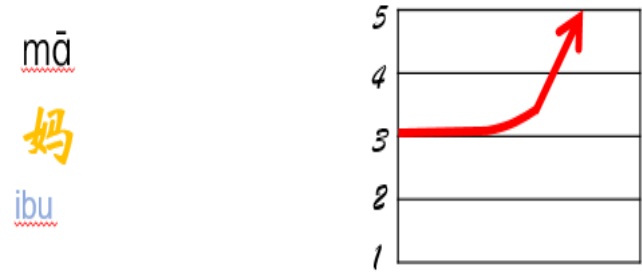

má

mă
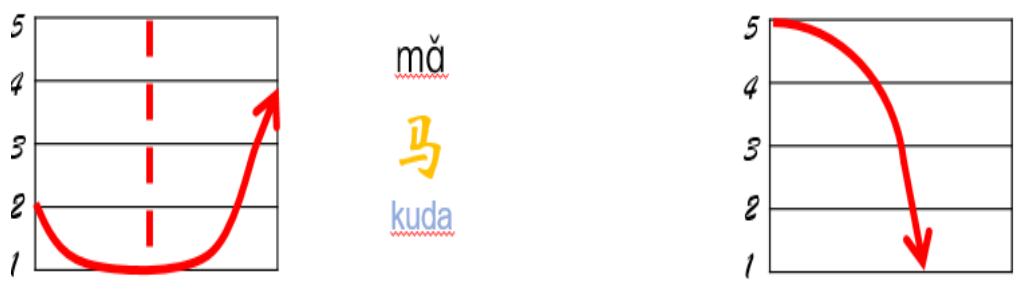

mà
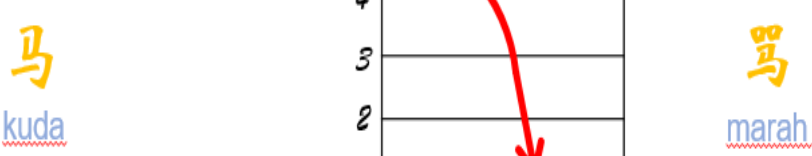

Gambar 1. Materi pelatihan Bahasa Mandarin Dasar 


\section{nǐn hăo}

\section{A: 您 好!}

nǐ men hăo

B: 你们 好!

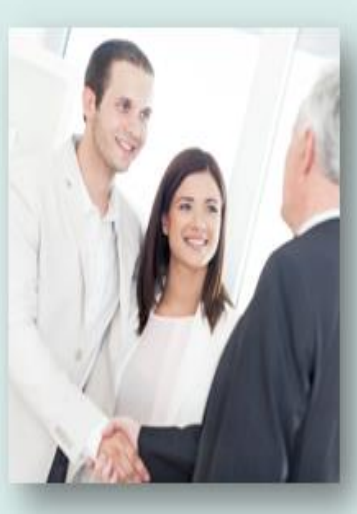

Gambar 2. Materi Dasar Percakapan Bahasa Mandarin

\section{认识独体字 Single-Component Characters}

（1）“口”, 本义是嘴巴, 字形像人张开的嘴巴。

The basic meaning of "口" is "mouth", and the character is shaped like a mouth.

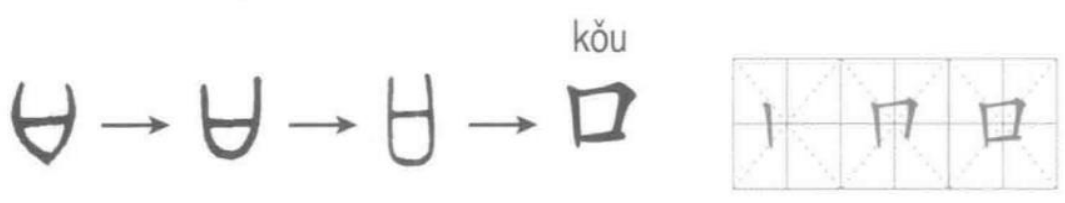

(2) “见”，字形上边是 “目”，下边是 “人”，意思是 “睁着眼睛看”。

Its traditional form of “见" has a “目 (eye)" on the top and a “人 (person)" at the bottom, meaning "watching with eyes open".

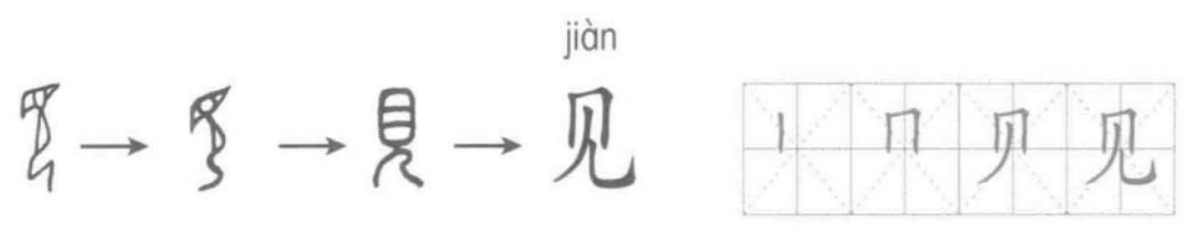

Gambar 3. Materi Dasar Perkenalan Huruf Mandarin

\section{Hasil dan Pembahasan}

\section{A. Pelaksanaan Kegiatan Pembelajaran Bahasa Mandarin}

Kegiatan Pengabdian kepada Masyarakat di GKKB Pontianak dilaksanakan pada bulan September dan Oktober 2019, yaitu dilakukan pada setiap hari Senin sore pukul 19.00-21.00. Kegiatan diadakan di Aula Betlehem lantai tiga gedung GKKB Pontianak, Jalan Gajah Mada No. 250. Kegiatan dilakukan dalam bentuk pemberian materi bahasa Mandarin melalui kegiatan workshop. 
Kegiatan dilakukan melalui tahapan-tahapan sebagai berikut:

1. Persiapan kegiatan meliputi:

a. Kegiatan survey tempat pengabdian kepada masayarakat yaitu di jalan gajahmada no.250.

b. Permohonan ijin kegiatan pengabdian masyarakat kepada pimpinan organisasi GKKB Pontianak.

c. Koordinasi dengan contact person pihak GKKB Pontianak yang memberikan informasi peserta workshop

d. Persiapan akomodasi selama kegiatan dan materi ajar Bahasa Mandarin yang sesuai dengan kondisi peserta, yaitu materi "Short Term Spoken Chinese" (materi terlampir); yang nantinya akan dibagikan kepada setiap peserta

e. Persiapan tempat kegiatan yaitu aula betlehem yang disedikan oleh pihak GKKB Pontianak yang sudah dilengkapi fasilitas yang cukup memadai untuk kegiatan pembelajaran bahasa mandarin.

2. Pembukaan kegiatan workshop dan perkenalan Tim Penyelenggara kegiatan pengabdian kepada masyarakat (dosen dan mahasiswa) dengan peserta GKKB Pontianak dan perkenalan singkat Prodi Pendidikan Bahasa Mandarin FKIP.

3. Pelaksanaan kegiatan pembelajaran berbahasa mandarin yang dibagi menjadi 4 pertemuan diantaranya: (1) Hanyu Pinyin; (2) Huruf Mandarin; (3) Tata bahasa: Kalimat Sederhana;

(4) Percakapan Bahasa Mandarin. Setiap kali pertemuan untuk kelas selama kurang lebih 2 (dua) jam.

4. Penutupan kegiatan, meliputi:

a. Penyampaian kata sambutan dan ucapan terimakasih oleh Ketua Pelaksana kegiatan Pengembangan kepada peserta dan pimpinan organisasi GKKB Pontianak.

b. Penyampaian kata sambutan dan ucapan terimakasih oleh perwakilan pimpinan organisasi GKKB Pontianak.

c. Penyampaian kesan pesan dan ucapan terima kasih oleh perwakilan peserta workshop.

d. Ramah tamah tim pelaksana kegiatan dan peserta.

\section{B. Sasaran}

Kegiatan Pembelajaran Berbahasa Mandarin ini ditujukan pada generasi muda organisasi GKKB Pontianak, dengan jumlah sebanyak 56 peserta yang tersebar dalam berbagai tingkatan kelas dan umur.

\section{Deskripsi Proses Kegiatan}

Kegiatan Pengabdian Kepada Masyarakat mengenai pembelajaran bahasa mandarin ini bertujuan untuk meningkatkan kemampuan berbahasa mandarin kepada generasi muda yang terlibat dalam organisasi GKKB Pontianak bisa termotivasi dan berminat untuk bisa belajar bahasa mandarin secara intensif. Kegiatan PKM ini secara umum berjalan dengan lancar. Pihak pimpinan organisasi sangat mendukung dalam mensukseskan kegiatan ini dengan terlibat aktif mempersiapkan tempat dan menginformasikan tentang adanya kegiatan ini kepada para peserta. Peserta Kegiatan ini adalah orang muda yang berusia di atas 16 tahun. Tempat yang digunakan adalah Aula Betlehem lantai tiga gedung GKKB Pontianak, Jalan Gajah Mada N0.250, yang memiliki fasilitas mendukung untuk pelaksanaan kegiatan, seperti ruangan ber-AC yang luas, kursi, mimbar, peralatan soundsytem.

Kegiatan pembelajaran berbahasa mandarin yang dibagi menjadi 4 pertemuan diantaranya: (1) Hanyu Pinyin; (2) Huruf Mandarin; (3) Tata bahasa: Kalimat Sederhana; (4) Percakapan Bahasa Mandarin. Kegiatan pembelajaran ini berlangsung selama kurang lebih dua jam yaitu dari pukul 19.00-21.00 WIB. 
Sebelum melakukan kegiatan pembelajaran, setiap pengajar memperkenalkan diri terlebih dahulu kemudian menyampaikan materi workshop. Selama proses kegiatan berlangsung tampak peserta sangat antusias menyimak isi materi yang disampaikan. Setelah menyampaikan materi, selain memberikan kesempatan peserta bertanya jawab, pemateri juga mengajukan pertanyaan bagi peserta, sehingga suasana pembelajaran menjadi lebih hidup.

\section{Hasil Kegiatan Pembelajaran}

Kegiatan pembelajaran bahasa mandarin bagi peserta organisasi GKKB Pontianak memberikan hasil sebagai berikut:

1. Meningkatnya pengetahuan peserta tentang materi dasar bahasa Mandarin di Organisasi GKKB Pontianak.

2. Tim Pelaksana Kegiatan telah membantu para generasi muda setempat untuk meningkatkan minat dan kemampuan berbahasa mandarin.

3. Membantu meningkatkan rasa kepedulian mahasiswa Program Studi Pendidikan Bahasa Mandarin Universitas Tanjungpura terhadap kondisi pendidikan di lingkungan masyarakat sekitanya.

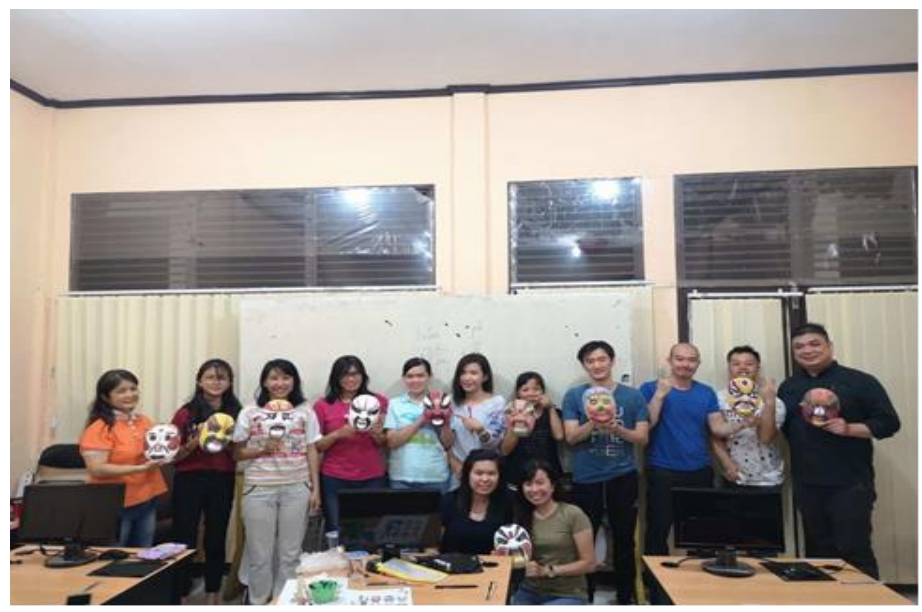

Gambar 3. Peserta Pelatihan Bahasa Mandarin

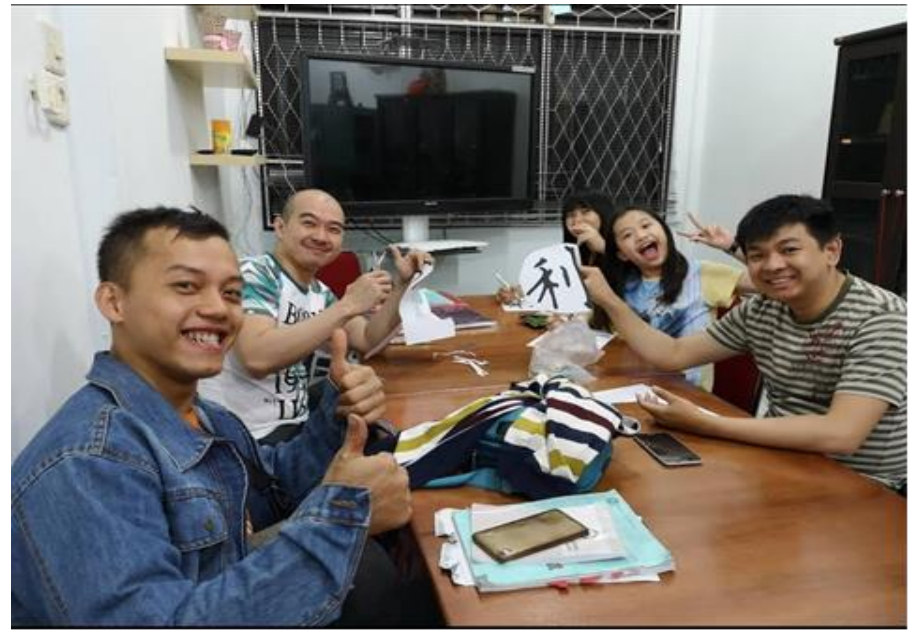

Gambar 4. Peserta Pelatihan Mengenal Huruf Mandarin 


\section{E. Respon dan Harapan Masyarakat}

Peserta yang mengikuti kegiatan ini menyambut baik kegiatan Pengabdian Kepada Masyarajat yang digelar oleh para dosen dan mahasiswa Program Studi Pendidikan Bahasa Mandarin Fakultas Keguruan dan Ilmu Pendidikan Universitas Tanjungpura. Mereka sangat mengapresiasi kegiatan ini, mengingat kegiatan ini merupakan salah satu cara untuk meningkatkan Kemampuan berbahasa mandarin bagi para generasi muda di lingkungan organisasi GKKB Pontianak. Harapan mereka adalah agar kedepan kegiatan yang serupa bisa kembali dihelat dalam jangka waktu yang lebih lama, agar bisa mencapai hasil yang lebih maksimal.

\section{F. Faktor Pendukung dan Penghambat}

Beberapa faktor yang mendukung terlaksananya kegiatan pengabdian pada masyarakat ini antara lain:

1. Besarnya minat dan antusiasme peserta selama kegiatan, sehingga kegiatan berlangsung dengan lancar dan efektif.

2. Peserta telah menyadari besarnya peranan bahasa Mandarin dalam perekonomian masyakat masa kini.

3. Besarnya dukungan dari pimpinan organisasi yang sangat berperandalam proses pelaksanaan kegiatan ini.

4. Semangat para mahasiswa yang aktif berkomunikasi dan membantu pelaksanaan kegitaan ini.

5. Kerjasama yang baik antara Tim Dosen, mahasiswa dan pimpinan organisasi di GKKB Pontianak sehingga kegiatan ini dapat berjalan dengan lancar dan aman.

Faktor penghambatnya diantaranya adalah:

1. Keterbatasan waktu kegiatan sehingga belum bisa membuahkan hasil yang maksimal.

2. Jangkauan peserta yang mengikuti workshop relatif masih sedikit karena kurangnya sosialisasi adanya kegiatan kepada anggota organisassi.

\section{G. Rekomendasi Rencana Tindak Lanjut}

Berdasarkan respon peserta yang sangat antusias menyambut kegiatan ini, dan evaluasi kegiatan yang dilakukan, maka rekomendasi rencana tindak lanjut kedepan adalah kegiatan pembelajarn bahasa mandarin sebaiknya dilakukan secara kontinyu dalam beberapa tahapan materi, seperti tingkat dasar dan tingkat menengah, agar bisa menjangkau lebih banyak tingkatan peserta dan organisasi lain yang membutuhkan.

\section{Simpulan}

Kegiatan Pengabdian kepada masyarakat yang dilaksanakan oleh tim dosen dan mahasiswa Prodi Pendidikan Bahasa Mandarin selama sebulan di GKKB Pontianak berjalan dengan lancar, aman dan sesuai dengan rencana. Kegiatan PKM ini merupakan hasil kerjasama tim antara dosen dan mahasiswa Prodi Pendidikan Bahasa Mandarin, dengan melibatkan 1 orang mahasiswa senior dan 2 mahasiswa baru. Semua tim terlibat aktif berperan dalam perencanaan, persiapan, pelaksanaan dan pelaporan PKM. Kegiatan PKM ini mendapatkan dukungan dari pimpinan dan peserta organisasi. Hal ini dilihat dari kesediaan pihak organisasi untuk menyediakan tempat dan fasilitas pelaksanaan kegiatan, antusias peserta dalam mengikuti kegiatan, kerjasama yang baik terjalin dengan pihak organisasi. Dari kegiatan 
pengabdian pada masyarakat ini diketahui bahwa: 1) Pengetahuan dan minat untuk belajar bahasa Mandarin menjadi meningkat, 2) Kemampuan berbahasa mandarin peserta meningkat. Adapun saran yang perlu diperhatikan adalah 1) Mengadakan kegiatan yang serupa pada khalayak sasaran yang berbeda seperti organisasi masyakat, perusahaan bidang jasa atau instansi-instansi pemerintah yang membutuhkan Bahasa Mandarin, 2) Adanya kesinambungan dan monitoring program setelah kegiatan pengabdian ini, sehingga hasil yang diperoleh sekarAng bisa ditingkatkan.

\section{Ucapan Terima Kasih}

Tim pengabdian mengucapkan terima kasih kepada berbagai pihak yang aktif terlibat dalam kegiatan ini sehingga kegiatan dapat terlaksana dengan baik. Ucapan terima kasih sebesar-besarnya juga kami sampaikan kepada pihak Gereja Kristen Kalimantan Barat yang telah membantu terlaksananya kegiatan ini.

\section{Daftar Pustaka}

Adji, F. (2017). Model Materi Ajar Membaca Bahasa Mandarin Berbasis Bahan Otentik. Buletin Al-Turas, 23(2), 287-299. https://doi.org/10.15408/bat.v23i2.6373

Badan Pengembangan dan Pembinaan Bahasa. (2020). KBBI Daring. Kementerian Pendidikan Dan Kebudayaan Republik Indonesia. https://kbbi.kemdikbud.go.id/

Haryanti, S. (2011). Penerapan Sistem Pembelajaran Bahasa Mandarin di Beberapa Sekolah di Indonesia. Lingua Cultura, 5(1), 136-143.

Herliana, M., \& Suryadi, M. (2019). Tindak Tutur Ilokusi Pengajar Pada Proses Pembelajaran Bahasa Mandarin. Jurnal Ilmiah Lingua Idea, 10(2), 89-105. https://doi.org/ 10.20884/1.jli.2019.10.2.2124

Jesslyn, J., \& Lystia, Z. (2019). Efektifitas Pembelajaran Bahasa Mandarin Bagi Lulusan Program Studi Sastra Cina Universitas Bunda Mulia Dalam Dunia Industri. Jurnal Bahasa Dan Budaya China, 2(2).

Kamil Malik. (2018). Aplikasi Media Pembelajaran Bahasa Mandarin Dengan Metode Tingshuofa Dilengkapi Voice Recognition Dictionary Berbasis Mobile.

Loris, H. (2017). Pengembangan Multimedia Intraktif Pembelajaran Bahasa Mandarin. Jurnal Teknologi Informasi \& Komunikasi Dalam Pendidikan, 4(2), 147-156. https:// doi.org/https://doi.org/10.24114/jtikp.v4i2.8762

Maria, M. (2017). Pembelajaran Bahasa Mandarin di Sekolah: Pendekatan dan Metode Alternatif. Jurnal Cakrawala Mandarin, 1(1), 1-10. https://doi.org/http://dx.doi.org/ 10.36279/apsmi.v1i1.25

Susanna, S. I. dan H. S. U. (2013). Pengembangan Multimedia dalam Pembelajaran Bahasa Mandarin untuk Kecakapan Menulis Kosakata di Kelas X SMA (Doctoral dissertation, Tanjungpura University).

Sutami, H. (2012). Fungsi dan Kedudukan Bahasa Mandarin di Indonesia. Paradigma: Jurnal $\begin{array}{lll}\text { Kajian } \quad \text { Budaya, } & 2, & 212-239 .\end{array}$ https://doi.org/http://dx.doi.org/10.17510/paradigma.v2i2.28

Syahputra, I. (2014). Strategi pembelajaran bahasa Inggris sebagai bahasa asing dalam meningkatkan kemampuan berbahasa siswa. Kutubkhanah, 17(1), 127-145. 